\title{
Building community together: towards equitable CSCL practices and processes
}

\author{
Carolyn P. Rosé ${ }^{1}$ - Sanna Järvelä ${ }^{2}$ \\ Published online: 8 September 2020 \\ (C) International Society of the Learning Sciences, Inc. 2020
}

\section{Introduction}

As a research community, the International Society of the Learning Sciences has always worked hard to maintain representation across multiple dimensions of diversity, including, but certainly not limited to regions and disciplines. The events of this past Summer challenge both our personal senses of safety and wellbeing as well as our bonds of community and joint engagement, which rest upon that foundation, a foundation meant to enable a productive synergy in the light of diversity. In this time that shakes us to our very core, we reflect on our research with renewed vigor, asking ourselves the hard questions of what we stand for as a community. In the research of the learning sciences, we strive to further STEM education (Matuk and Linn 2018; Solli et al. 2018), but now our faith even in science is challenged as we look to an uncertain future with respect to a vaccine for COVID 19. In our CSCL research, we advocate for support that increases transactivity in the collaborative interactions supported in our learning environments (van Heijst et al. 2019), but in both our personal and professional lives we struggle to engage with communities whose political beliefs are far different from our own. We conduct research in the hopes to foster a sense of agency and self-efficacy in the students our research touches (Lee and Song 2016; Tchounikine 2019), and yet the natural disasters around us challenge the extent to which we can truly believe we are in control. In the midst of these shifting sands, we offer to this community the September edition of the International Journal of Computer-Supported Collaborative learning, comprising four full articles and one squib, all of which speak to these themes, with a consistent deep inspection of processes of collaboration. In the words of Gutiérrez and Jurow (2016), we look hopefully into these processes "that empower learners to become authors of their own futures". Though we as a journal community greatly value both large scale quantitative research (Holtz et al.

Carolyn P. Rosé

cp3a@andrew.cmu.edu

Sanna Järvelä

sanna.jarvela@oulu.fi

1 Carnegie Mellon University Language Technologies Institute and HCI Institute, Pittsburgh, PA, USA

2 University of Oulu, Oulu, Finland 
2018) and deep, reflective qualitative research, in this time of quiet reflection, we offer a collection fully within the qualitative tradition, though we look forward to strong empirical articles in future editions of the journal.

\section{Making sense through interaction}

The first three articles of this edition present a progression of methodologies for qualitative inspection of collaborative discussion processes, each of which brings novelty in its methods as well as in the questions asked of the data.

In the first such article, "Data Wrangling Practices and Learning with Aggregated Data in Talk-in-Interaction", Shiyan Jiang and Jennifer Kahn offer a timely investigation of collaborative sense making regarding data representations, building on past CSCL work in which students similarly worked with interactive visual representations (Ingulfsen et al. 2018; Davis et al. 2015; Oner 2016). This paper delves deeply into the sense making processes students engage in as they work with novel, interactive data visualization tools that enable them to interact with representations of their respective family histories. During the process they reason about the data as they work towards constructing a narrative describing their emerging understanding of the data. The teacher plays a critical role in scaffolding their interaction with the data and narrative construction through their collaborative discourse with the students as they think alongside the students in their sensemaking work. Videos of the collaborative interactions between teachers and students are analyzed in depth, both in terms of the discussion and in terms of observed gestures. Though the primary collaboration that is in evidence in this paper is that between the teacher and students rather than between students, the nature of the collaborative discourse is telling, and a future vision where the findings can be applied in collaborative learning contexts where students work together on such sense making and narrative construction activities are discussed. In addition to the ideas for future application in CSCL settings offered by the article, it is noteworthy that we can observe a collaborative sensemaking process around us as we observe in the international press evidence of intertextual interactions implicit within the narrative renditions of sensemaking about data related to COVID 19, the effects of mitigation strategies, and the race for a vaccine, some of which are presented to the world through interactive data visualizations as in the Jiang and Kahn article. It is a challenge for this CSCL community to reflect on what we learn from this article about how we as researchers first join this extended conversation as we ourselves interact with those texts. Then as individuals more savvy about scientific processes than many of our neighbors, friends, and family members, we may also play the role of the teacher as we engage with our communities in the interaction that ensues.

The second article, by Susan Margaret Bridges, Cindy Hmelo-Silver, Lap Ki Chan, Judith Green, and Asmaline Saleh, is entitled "Dialogic intervisualizing in multimodal inquiry". Similar to Jiang and Kahn, this article highlights the important role of the facilitator, this time in connection with Problem Based Learning (PBL) specifically in a medical school context. Also similar to Jiang and Kahn, they conduct an extensive analysis of video data, expanding upon earlier Sociocutural analyses of video data (Bezemer 2017; Danish 2018; Kershner et al. 2010; Koschmann 1999; Steier et al. 2019). Again, as in the previous article, students and facilitator work together to co-construct a narrative of sorts. What is particular to their approach is an innovative methodological lens referred to as Interactional Ethnography (IE), which is a logic-of-inquiry that can be used to examine collaborative processes as 
undergraduate students and their facilitator "access, review, appropriate and devise multimodal digital and visual texts". They refer to their novel conceptualization of the co-constructive process over time as dialogic intervisualizing, designed to capture the interplay between the conversation, the broader collaborative problem solving processes, and the evolving artifacts produced during the interaction. They draw heavily from sociolinguistics, especially Silverstein's (2003) concept of “indexical order", which offers theoretical tools for explaining how conceptual objects can be decontextualized and then recontextualized to transform and then move them between modalities or between distinct contexts within the same modality. Moving forward, we expect learning in a medical context to grow in prominence over the next several years, and thus this study provides needed insights about how students learn together as they prepare to serve as doctors in the wake of a pandemic.

The third article brings in a less frequently studied context in the CSCL literature, but one that we would like to see more of, specifically collaboration in maker spaces. The devised methodology may be the most innovative of the three, building on a textiles metaphor to expand upon earlier process visualization research that grows out of the same PBL literature that formed the backdrop for the Bridges et al. article (Hmelo-Silver et al. 2011). In particular, Sini Riikonen, Pirita Seitamaa-Hakkarainen \& Kai Hakkarainen present an article entitled "Bringing maker practices to school: Tracing discursive and materially mediated aspects of student teams' collaborative making processes". Their innovative methods were developed for the purpose of investigating socially and materially mediated collaborative processes of coinvention as teams of seventh-grade students engaged in collaborative making. The interesting insights that become visible in the analysis illustrate the ways in which social-discursive and materially mediated aspects of making are intertwined, and that this entanglement must be an integral part of elucidating these processes. An added challenge is that the objects of coconstruction evolve and change throughout the interaction. By providing visibility into this entanglement, the analysis is able to illustrate how successful teams were able to sort out their coordination challenges during the co-invention process.

Like the earlier two papers, the important role of the facilitator is in evidence here. They conclude by acknowledging the resources in terms of "design, fabrication methods, mechanics and materials, and the pedagogics of invention and making" that teachers bring to the table. Though CSCL values interaction between peers first and foremost, the three articles in this section highlight the extent to which this collaboration does not come without support, and in particular, offer three examples where that support is offered in human form with a personal touch. The teachers and facilitators who provided scaffolding in these three studies bring value in their human touch to these collaborative encounters, participating within the conversational interactions in richer ways than automated conversational agents will ever be able to. In the midst of the changing landscape of education during COVID 19, in as much as our community brings expertise in the form of automated structuring and support for collaboration, let us stop here to appreciate the value of the human touch, even as we are keenly aware of its lessening availability during this time.

\section{Building community and building equity together}

The final full article and squib each touch upon the theme of scaffolded knowledge building. First, Susan Yoon presents an article entitled "Encouraging Collaboration and Building Community in Online Asynchronous Professional Development: Designing for Social 
Capital" in which a deployment of scaffolding for collaborative knowledge building is investigated in the midst of an online teacher professional development community.

Professional development is a key aspect of the continuing education of teachers especially in the face of increasing demands in terms of changing standards, but generally comes with a cost in terms of the human effort of facilitators and time taken away from instruction. Building online support communities fostering this development has the potential to lessen both costs as emerging social structures provide an environment in which teachers provide resources for each other (Lieberman and Mace 2010; Hatch et al. 2006; Booth 2012) in terms of asynchronous joint problem solving regarding problems they each experience in their own respective work contexts (Alterman and Harsch 2017; Jeong et al. 2017). Here, Social Capital is considered evidence within a network of the sharing of knowledge and resources as well as providing access to expertise. In particular, this article reports on an intervention administered to teachers that involved both social capital mechanisms and teacher learning in the midst of an online professional development course, with the goal of enhancing online participation in the course and collaborative knowledge building. The course afforded asynchronous engagement, which was necessary given the very demanding schedules of teachers, however the asychronicity at the same time posed challenges for joint engagement in knowledge building. To address the challenges, automated scaffolds for interaction processes were provided as part of the intervention. Transactivity, with its underlying social underpinnings (Gweon et al. 2013) and evidence of correlation with expertise transfer (Gweon et al. 2011) was measured as a process indicator of the success of the intervention. The results point both to the overall success of the intervention and the importance of social capital in online professional development communities as well as to important areas for potential improvement in future iterations. As the extended community of instructors, including both K12 and post-secondary, step out of this Summer and into a Fall, we walk forward into new challenges with respect to returning to face-to-face instruction, and the potential for new waves of the virus. This article speaks of how research in CSCL can be used to build community among teachers, and thus increase the amount of available support for these instructors as they reach out for one another, even in the midst of their busy schedules, and under increased strain and danger.

The final article, a squib entitled "Finding a Place for Equity in CSCL: A Lever for Sustained Educational Change" by Suraj Uttamchandani, Ayesha Bhimdiwala, and Cindy Hmelo-Silver, bring us full circle to issues of equity in line with concerns raised at the start of this editorial. This author team agrees with Hod et al. (2018) in their expression of hope in the potential of CSCL to contribute towards large scale educational change. Their overall aim is to argue in favor of what they refer to as "ambitious learning practices", which they argue are practices that "can empower students, support shared meaning-making, and potentially disrupt social inequality". They connect discussion of these issues with a current trend in CSCL research, namely adaptive forms of scripted collaboration (Wang et al. 2017), especially in connection with conversational agents (Tegos et al. 2016; Rosé and Ferschke 2016). In their article they weigh and balance their perspective on the potential costs and benefits of automated forms of adaptive collaborative learning support, raising questions related to blind spots, bias, or lack of nuance in underlying model predictions. These are concerns raised within the popular press regarding increasing awareness of Artificial Intelligence (AI) applied in many every day experiences and connect in obvious ways with the issues regarding equity and diversity raised earlier. It should be well noted that these are issues very much at the forefront of research in AI and Machine Learning (ML), especially in the area of AI transparency, explainability, and fairness (Holstein et al. 2019; Shah and Lipton 2020; 
Wang et al. 2020), and the popular press portrayal as AI alternately as hero and foe can sometimes be taken up and amplified, even by experts of other fields, to the detriment of all. Taking instead a reasonable stance, Uttamchandani and colleagues end their use case discussion reaffirming the potential for these forms of collaboration support to bring positive change. To ensure a positive change, the topics surrounding fairness in machine learning should be jointly investigated going forward by CSCL researchers in collaboration with core Machine Learning researchers in order that deep insights into the root causes of potential unfairness in trained models can properly be taken into account alongside deep expertise into the context of use. In this way, all of the necessary ingredients will be at hand to enable innovating effective mitigation strategies.

\section{Moving ahead call for special issue proposals}

As we move forward, step-by-step, let us find inspiration in our research as it reminds us of the important work we have cut out for ourselves. In that light, we look forward to new submissions, building upon the traditions of rigorous empiricism as well as thick description that are both strengths, and stretching us in new directions that give us hope and a future.

In the spirit of eagerly pursuing an increased flow of submissions to the journal, for the first time, the co-editors-in-chief announce an Open Call for a Special Issue, which offers a team of authors the opportunity to work on an interconnected set of papers about an innovative theme. This 2021 Open Call for a Special Issue of the International Journal of Computer-Supported Collaborative Learning solicits high-quality proposals that will be evaluated in a highly competitive procedure.

The call welcomes contributions covering any topics within the scope of the journal. The journal serves as a forum for experts from such disciplines as education, computer science, information technology, psychology, communications, linguistics, anthropology, sociology, and business. Articles investigate how to design the technological settings for collaboration and how people learn in the context of collaborative activity. Thus, the papers included in special issue proposals may represent a variety of theoretical perspectives and different methodological approaches. The major criteria in the review and the selection process concern the significance of the contribution to the area of Computer-Supported Collaborative Learning, and the rigor of the study. Proposals for Special Issues should be sent by December 15, 2020 directly to the co-Editors-in-Chief, Professors Sanna Järvelä (sanna.jarvela@oulu.fi) and Carolyn Rosé (cprose@cs.cmu.edu). Detailed requirements and process information can be found on the ISLS website.

\section{References}

Alterman, R., \& Harsch, K. (2017). A more reflective form of joint problem solving. International Journal of Computer-Supported Collaborative Learning, 12(1), 9-33.

Bezemer, J. (2017). Visual research in clinical education. Medical Education, 51(1), 105-113. https://doi. org/10.1111/medu.13163.

Booth, S. E. (2012). Cultivating knowledge sharing and trust in online communities for educators. Journal of Educational Computing Research, 47(1), 1-31.

Danish, J.A. (2018). Designing for technology enhanced activity to support learning, The Emerging Learning Design Journal, 1(1), article 1. 
Davis, P., Horn, M., Block, F., Phillips, B., Evans, E. M., Diamond, J., \& Shen, C. (2015). "Whoa! We're going deep in the trees!": Patterns of collaboration around an interactive information visualization exhibit. International Journal of Computer-Supported Collaborative Learning, 10(1), 53-76.

Gutiérrez, K. D., \& Jurow, A. S. (2016). Social design experiments: Toward equity by design. Journal of the Learning Sciences, 25(4), 565-598.

Gweon, G., Kane, A., Rosé, C. P. (2011). Facilitating knowledge transfer between groups through idea coconstruction processes, in Proceedings of the Annual Meeting of the Interdisciplinary Network for Group Research (INGRoup), Minneapolis, MN.

Gweon, G., Jain, M., Mc Donough, J., Raj, B., \& Rosé, C. P. (2013). Measuring prevalence of other-oriented transactive contributions using an automated measure of speech style accommodation. International Journal of Computer-Supported Collaborative Learning, 8(2), 245-265. https://doi.org/10.1007/s11412-013-91725.

Hatch, T., White, M. E., Raley, J., Austin, K., Capitelli, S., \& Faigenbaum, D. (2006). Into the classroom: Developing the scholarship of teaching and learning. Jossey-Bass.

Hmelo-Silver, C., Jordan, R., Liu, L., \& Chernobilsky, E. (2011). Representational tools for understanding complex computer-supportive collaborative learning environments. In S. Puntambekar, G. Erkens, \& C. Hmelo-Silver (Eds.), Analyzing interactions in CSCL: Methods, approaches and issues (pp. 83-106). London: Springer.

Hod, Y., Sagy, O., \& Kali, Y. (2018). The opportunities of networks of research-practice partnerships and why CSCL should not give up on large-scale educational change. International Journal of Computer-Supported Collaborative Learning, 13(4), 457-466.

Holstein, K., Wortman Vaughan, J., Daumé III, H., Dudik, M., \& Wallach, H. (2019). Improving fairness in machine learning systems: What do industry practitioners need?. In Proceedings of the 2019 CHI Conference on Human Factors in Computing Systems (pp. 1-16).

Holtz, P., Kimmerle, J., \& Cress, U. (2018). Using big data techniques for measuring productive friction in mass collaboration online environments. International Journal of Computer-Supported Collaborative Learning, 13(4), 439-456.

Ingulfsen, L., Furberg, A., \& Strømme, T. A. (2018). Students' engagement with real-time graphs in CSCL settings: Scrutinizing the role of teacher support. International Journal of Computer-Supported Collaborative Learning, 13(4), 365-390.

Jeong, H., Cress, U., Moskaliuk, J., \& Kimmerle, J. (2017). Joint interactions in large online knowledge communities: The A3C framework. International Journal of Computer-Supported Collaborative Learning, 12(2), 133-151.

Kershner, R., Mercer, N., Warwick, P., \& Staarman, J. K. (2010). Can the interactive whiteboard support young children's collaborative communication and thinking in classroom science activities? International Journal of Computer-Supported Collaborative Learning, 5(4), 359-383.

Koschmann, T. (1999). Toward a dialogic theory of learning: Bakhtin's contribution to understanding learning in settings of collaboration. Proceedings of the 1999 conference on Computer Support for Collaborative Learning.

Lee, S., \& Song, K. (2016). Exploring the relationship between resistance and perspectival understanding in computer-mediated discussions. International Journal of Computer-Supported Collaborative Learning, 11(1), 41-58.

Lieberman, A., \& Mace, D. P. (2010). Making practice public: Teacher learning in the 21 st century. Journal of Teacher Education, 61(1-2), 77-88.

Matuk, C., \& Linn, M. C. (2018). Why and how do middle school students exchange ideas during science inquiry? International Journal of Computer-Supported Collaborative Learning, 13(3), 263-299.

Oner, D. (2016). Tracing the change in discourse in a collaborative dynamic geometry environment: From visual to more mathematical. International Journal of Computer-Supported Collaborative Learning, 11(1), 59-88.

Rosé, C. P., \& Ferschke, O. (2016). Technology support for discussion based learning: From computer supported collaborative learning to the future of massive open online courses. International Journal of Artificial Intelligence in Education, 26(2), 660-678.

Shah, N. \& Lipton, Z. (2020). SIGMOD 2020 Tutorial on Fairness and Bias in Peer Review and Other Sociotechnical Intelligent Systems, Proceedings of the 2020 ACM SIGMOD International Conference on Management of Data June 2020 Pages 2637-2640 https://doi.org/10.1145/3318464.3383129

Silverstein, M. (2003). Indexical order and the dialectics of sociolinguistic life. Language \& Communication, 23(3), 193-229. Doi: https://doi.org/10.1016/S0271-5309(03)00013-2.

Solli, A., Mäkitalo, Å., \& Hillman, T. (2018). Rendering controversial socioscientific issues legible through digital mapping tools. International Journal of Computer-Supported Collaborative Learning, 13(4), 391418 . 
Steier, R., Kersting, M., \& Silseth, K. (2019). Imagining with improvised representations in CSCL environments. International Journal of Computer-Supported Collaborative Learning, 14(1), 109-136.

Tchounikine, P. (2019). Learners' agency and CSCL technologies: Towards an emancipatory perspective. International Journal of Computer-Supported Collaborative Learning, 14(2), 237-250.

Tegos, S., Demetriadis, S., Papadopoulos, P. M., \& Weinberger, A. (2016). Conversational agents for academically productive talk: A comparison of directed and undirected agent interventions. International Journal of Computer-Supported Collaborative Learning, 11(4), 417-440.

van Heijst, H., de Jong, F. P., Van Aalst, J., De Hoog, N., \& Kirschner, P. A. (2019). Socio-cognitive openness in online knowledge building discourse: Does openness keep conversations going? International Journal of Computer-Supported Collaborative Learning, 14(2), 165-184.

Wang, X., Kollar, I., \& Stegmann, K. (2017). Adaptable scripting to foster regulation processes and skills in computer-supported collaborative learning. International Journal of Computer-Supported Collaborative Learning, 12(2), 153-172.

Wang, J., Shah, N., \& Ravi, R. (2020, June). Stretching the effectiveness of MLE from accuracy to Bias for pairwise comparisons. Proceedings of the International Conference on Artificial Intelligence and Statistics (pp. 66-76).

Publisher's note Springer Nature remains neutral with regard to jurisdictional claims in published maps and institutional affiliations. 